\title{
Brote de Gastroenteritis por Vibrio parahaemolyticus en Chile
}

\author{
ANDREA M. OLEA(1), CLAUDIA GONZÁLEZ(1), MÓNICA CHIU(1), CLELIA VAILEBUONA(1), \\ MARITZA LABRANA(2), FRANCO MARTINIELLO(2)
}

\section{INTRODUCCIÓN}

El Vibrio parahaemolyticus es una bacteria entérica, cuyo hábitat natural son las costas marinas, pues requiere sal para su desarrollo. En la época de calor se encuentra en las aguas litorales y mariscos bivalvos, mientras que en la época fría se encuentra en los sedimentos marinos.

Se han notificado brotes en muchos países del mundo, donde la fuente inculpada han sido los mariscos crudos o mal cocidos (ostras y almejas principalmente). Los casos se presentan con mayor frecuencia en meses cálidos.

La transmisión se produce por la ingestión de mariscos, especialmente bivalvos, crudos o mal cocidos. También se puede dar por contaminación cruzada de otros alimentos (por la manipulación incorrecta de mariscos crudos). La congelación inapropiada de productos del mar contaminados favorece su proliferación y la posibilidad de infectar. No se transmite de persona a persona.

El período de incubación es de 12 a 24 hrs, luego del cual se produce un cuadro intestinal (enteritis) caracterizado por diarrea acuosa y cólicos abdominales, que puede acompañarse de náuseas, vómitos, fiebre y cefalea. Generalmente es autolimitado y dura alrededor de 3 días (rango 1 a 7). La muerte por esta causa es muy rara. En brotes ocurridos en Australia, Estados Unidos y Reino Unido, la letalidad no supera el $0,5 \%$. La medida principal es la hidratación para reponer los fluidos perdidos por la diarrea.

En tanto, como medida de prevención, lo más importante es el consumo de los productos del mar bien cocidos y mantener una adecuada higiene en la preparación de éstos.

\section{Situación epidemiológica}

El Vibrio parahaemolyticus (VP) es un enteropatógeno emergente en Chile.

Antes de 1997, el VP se encontraba en forma esporádica. Entre 1992 y 1997, el Instituto de Salud Pública (ISP), recibió 30 aislamientos de muestras clínicas provenientes de los Hospitales Regionales para su identificación. Sin embargo, un brote ocurrido en Antofagasta entre noviembre de 1997 a marzo de 1998 , elevó la cifra a 300.

Entre enero y marzo del 2004, un segundo brote afectó a más de 1.500 personas, mayoritariamente adultos, en el Servicio Llanquihue, Chiloé y Palena (Llanchipal), en el sur del pais. Las cepas aisladas fueron enviadas al ISP, confirmando que se trataba de Vibrio parahemolyticus. Además, fue confirmada la presencia de toxina TDH (productora de intoxicaciones) de VP en las muestras de mariscos, suspendiendo la extracción durante la temporada de mayor demanda. Secundariamente, previo al cese de la sustracción de mariscos, se produjeron brotes en la RM, V, VIII y IX regiones.

El análisis de los aislamientos clínicos de Vibrio parahaemolyticus provenientes de los brotes de Llanchipal (2004) y Antofagasta

\footnotetext{
(1) Departamento de Epidemiología. Ministerio de Salud.

a) Departanento Conunicaciones y Relaciones Públicas. Ministerio de Salud
} 
(1998), indicaron que 23 de 24 aislamientos de Puerto Montt y 19 de 20 en Antofagasta, correspondieron al clon pandémico $(\mathrm{O} 3 \mathrm{~K} 6)^{*}$ que emergió en el Sudeste Asiático en 1996**. Esto demuestra que la diseminación del clon pandémico tardó menos de 2 años en llegar al hemisferio sur desde su abrupta aparición en la India en 1996.

Sin embargo, de acuerdo a los resultados de los análisis realizados en el ISP, las muestras ambientales (mariscos) presentan una baja carga de contaminación por Vibrio parahaemolitycus, un gran polimorfismo genético y muy baja frecuencia de $\mathrm{TDH}^{* * *}(99 \%$ cepas no patógenas) $)^{* * * *}$.

\section{Brote 2005}

El 4 de enero, comienzan a aparecer casos de gastroenteritis compatibles con un cuadro de intoxicación por Vibrio parahacmolitycus en la $\mathrm{X}$ región, extendiéndose a la $\mathrm{V}$ región los primeros dias de febrero. Posteriormente, aparecen casos en la Región Metropolitana y resto del país con excepción de la 11 y III regiones. El total acumulado al 23 de marzo asciende a 10.491 casos, 789 confirmados por el Instituto de Salud Pública (ISP) y el resto, por nexo epidemiológico.

El 35\% del total de casos corresponde a la $\mathrm{X}$ región, afectando ligeramente más a hombres $(52 \%)$ y mayoritariamente a adultos (mediana de edad de 39 años).

La Figura 1 muestra los casos ocurridos en el país a contar del 15 de febrero en adelante. Se observa una clara tendencia al descenso desde el 21 de febrero, con leves repuntes durante los fines de semana.

\section{Presentación clínica}

De acuerdo al análisis de la encuesta realizada a los casos consultantes en la $\mathrm{X}$ región, el cuadro clínico se caracteriza por dolor abdominal, diarrea, vómitos y fiebre, como se presenta en la Tabla 1.

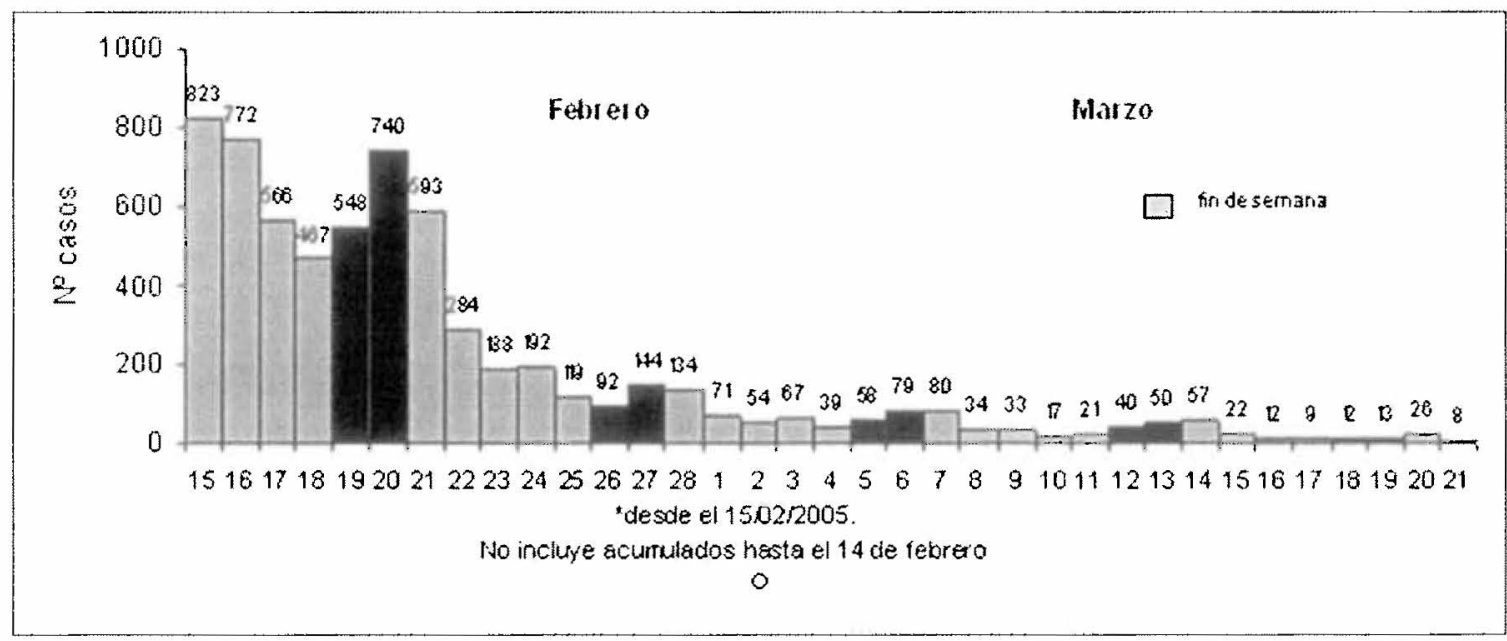

Figura 1. Casos de intoxicación por Vibrio parahaemolyticus. Totales país*.

* Fn febrero de 1996 en Calcuta, India, se detecta por primera vez un nuevo clon de $V$ parahaemolyticus perteneciente al serotipo 03:K6, responsable de un gran aumento de los casos de enfermedad diarreica en esa zona.

* Narjol González Escalona, Viviana Cachicas, Claudia Acevedo, María L. Rioseco, Juan A. Vergara, Felipe Cabello, dame Romero y Romilio Espejo. Vibrio parahamolvticus Diarrea, Chile, 1998 and 2004. Emerging Infectious Diseases, vol. 11, No I, January 2005.

*** La toxina termoestable directa (THD) es el factor de virulencia más importante y el que ocasiona la diarrea.

**** Hormazábal J C., Fernández.J., Silva W., Olivares B, Heitmann J. Caracterización Molecular de aislamientos de Vibrio parahacmolyticus, ISP-2004. Sección Bacteriologia. Subdepartamento de Microbiologia Clínica. Unidad de Desarrollo, Instituto de Salud Pública de Chile. 
Tabla 1. Frecuencia de signos y síntomas

\begin{tabular}{lc}
\hline Síntomas & Porcentaje de frecuencia \\
\hline Dolor abdominal & $90 \%$ \\
Náuseas y vómitos & $89 \%$ \\
Diarrea sin sangre & $80 \%$ \\
Fiebre & $77 \%$ \\
Deshidratación & $38 \%$ \\
Hormigueo & $16 \%$ \\
Calambres & $16 \%$ \\
Diarrea con sangre & $6 \%$ \\
Cefalea & $4 \%$ \\
\hline
\end{tabular}

$(\mathrm{n}=502$ acumulados al dia 12 de febrero 2005$)$.

Elaborado por Departamento de Epidemiología, Ministerio de Salud de Chile.

Fuente: SEREMI $X$ región.

Respecto a la gravedad, medida en términos de hospitalización, ésta fue indicada en el 0,6\% de los casos (59). La VI región presentó una frecuencia de hospitalización de un 1,8\% del total de casos regionales, mientras que la $\mathrm{X}$ región que concentra el $35 \%$ de los casos totales del pais, presentó un $1 \%$ de hospitalizaciones (33 casos). De acuerdo al análisis realizado por la Seremi de la X región, los hospitalizados corresponden a adultos, con una mediana de edad de 39 años (rango:14 - 74 años), sin diferencias por sexo. A la fecha, sólo una muerte atribuible al brote por nexo epidemiológico.

\section{COMENTARIO}

El brote ocurrido en el país, se caracterizó por su magnitud y extensa distribución geográfica. Las muestras ambientales presentaron una baja carga bacteriana en los puntos de extracción con un $99 \%$ de cepas no patógenas; a diferencia de los aislamientos clínicos, donde el $90 \%$ corresponde al clon pandémico (O3K6).

Estas características abrieron una serie de interrogantes respecto al comportamiento del Vibrio parahaemolyticus, que a su vez, definieron algunas líneas de investigación que intentarán responderlas. Entre ellas, se plantea la cuantificación de la carga de Vibrio parahaemolyticus en mariscos en puntos de extracción, distribución y venta y un estudio de termorresistencia de Vibrio parahaemolyticus en bivalvos, a diferentes inóculos. Paralelamente, se desarrollará un estudio ecológico que correlaciones las variables ambientales que impactan en los niveles de contaminación de los mariscos, a fin de contar con un modelo predictivo que permita anticipar la ocurrencia de brotes.

En relación al comportamiento del Vibrio parahaemolyticus en las personas, se está evaluando el diseño de un estudio de casos y controles que permita identificar factores de riesgo.

Con ello, se intenta conocer la distribución del Vibrio parahaemolyticus en las costas chilenas, el comportamiento de las cepas predominantes en relación a su capacidad y condiciones de multiplicación, sensibilidad antibiótica, competencia con otras cepas, carga infectante $y$, finalmente, contar con un modelo predictivo.

Usted puede comentar éste y otros artículos publicados en la Revista Chilena de Salud Pública, enviando un correo electrónico a revistasp@med.uchile.cl 